\title{
Safety and Effectiveness of Human Stem Cells for Bronchopulmonary Dysplasia in Preterm Infants: A Systematic Review and Meta-analysis
}

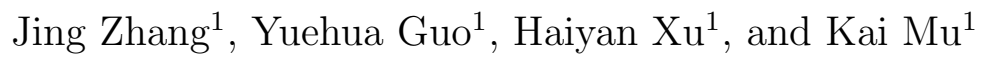 \\ ${ }^{1}$ First Affiliated Hospital of Shandong First Medical University
}

November 3, 2020

\begin{abstract}
Objective: To evaluate the safety and efficacy of human stem cells for bronchopulmonary dysplasia in preterm infants. Study design: From inception to September 2020, the PubMed, Web of Science, Cochrane Library and CNKI databases as well as ClinicalTrials.gov were searched for relevant reports. All the clinical trials, case reports, case series and letters were included. The included results were analyzed by Stata 16.0. Results: There were no statistically significant differences between the trial and control groups with respect to the number of deaths (OR $[95 \% \mathrm{CI}]: 0.619[0.089,4.316]$ ) or bronchopulmonary dysplasia cases (OR [95\% CI]: $1.138[0.040,32.36])$. The incidences of serious adverse events and dose-limiting toxicities were not significantly different between the two groups. There was a significant statistical difference between the trial and control groups in the mechanical ventilation duration $(\mathrm{P}<0.05)$ and duration of oxygen $(\mathrm{P}<0.05)$. Conclusion: The infusion of human cord blood stem cells into premature infants does not increase the risk of serious adverse events or death, and this therapy may decrease the mechanical ventilation duration and duration of oxygen administration.
\end{abstract}

\section{Introduction}

Bronchopulmonary dysplasia (BPD) is a chronic lung disease in extremely preterm infants and very preterm infants (gestational age $<32$ weeks). With improvements in neonatal intensive care, the survival rate of preterm infants has increased significantly. BPD is the most common complication in extremely low gestational age newborns or very preterm infants and is increasing in prevalence ${ }^{1}$. The main cohort studies (including studies in China, India, the Canadian Neonatal Network, the Swiss Neonatal Network, and the Korean Neonatal Network) have suggested that the BPD incidence is $11 \%-50 \%^{2-6}$. The younger the gestational age is, the higher the incidence of BPD. In the neonatal period, the main clinical manifestations of BPD include a progressive increase in respiratory support requirements, persistent lung arterial hypertension, hypercapnia, diuretic dependence, and capillary leakage, etc ${ }^{7}$. Long-term complications of BPD include abnormal lung function and structure, cardiovascular diseases ${ }^{8-10}$ and impaired long-term neurodevelopment ${ }^{11}$, which will increase familial and social medical $\operatorname{costs}^{12}$. Currently, there is no effective treatment method for BPD. The prevention and treatment for BPD include avoiding intubation and ventilation, caffeine, corticosteroids and inhaled nitric oxide ${ }^{13}$. Corticosteroids can reduce chronic oxygen dependence and the incidence of BPD, but the neurodevelopmental safety of corticosteroids in extremely preterm infants needs to be assessed ${ }^{14,15}$. Nitric oxide inhalation can improve respiratory symptoms and decrease brain damage in preterm infants, but it has no definite effect on the development of BPD in white or Hispanic groups ${ }^{16,17}$.

In recent years, advances in regenerative medicine have provided new ideas for the treatment of BPD. Several preclinical studies have shown that human stem cells may improve alveolarization and pulmonary hypertension by participating in the repair of damaged tissues and immune regulation ${ }^{18}$ and reduce lung inflammation by reducing tumor necrosis factor and increasing interleukin-10 ${ }^{19}$. Vascular endothelial growth 
factor secreted by human stem cells can promote BPD vascular development and repair ${ }^{20}$. A meta-analysis of preclinical studies that assessed the efficacy of mesenchymal stem cells (MSCs) therapy in BPD showed that MSCs treatment had a significant benefit for outcome measures (including alveolarization, lung inflammation and pulmonary hypertension $)^{21}$. There have been few systematic reviews and/or meta-analyses on the safety of human stem cells in preterm infants and their therapeutic potential for clinical BPD to date. To explore the evidence-based translation of this promising human stem cell therapy into the clinic for patients at risk of developing BPD, we performed this meta-analysis to assess the current clinical evidence to help guide clinical treatment.

\section{METHODS}

\section{Search Strategy}

We followed the recommendations of the PRISMA-P (preferred reporting items for systematic review and meta-analysis protocols) ${ }^{22}$ and Cochrane collaboration recommendations ${ }^{23}$. Two independent reviewers (J.Z. and Y.G.) searched the keywords in PubMed, Web of Science, Cochrane Library, CNKI and ClinicalTrials.gov using keywords from inception to September 2020. The following keywords were used in PubMed: "stem cells" or "cord blood cell" or "human umbilical cord blood", and "preterm infants" or "infant" or "neonates", and "lung injury".

All the clinical trials, case reports, case series and letters were analyzed. The inclusion criteria were as follows: (1) no language restriction; and (2) preterm infants born at less than 37 weeks' gestational age. Any pre-clinical studies were excluded.

\section{Data Analysis}

All of the data were extracted from each study, and the risk of bias was assessed by two independent reviewers. Discrepancies in quality assessment ratings between reviewers were resolved by the third reviewer (H.X.). The data extracted from each study included authors, year of publication, sample size, type of study, study duration, characteristics of the sample population, type of stem cells, dosage of administration, BPD diagnosis, and quality assessment. The primary outcomes included: (1) the incidence of bronchopulmonary dysplasia (BPD) or death and (2) the incidence of serious adverse events (SAEs) ${ }^{24}$ or dose-limiting toxicities (DLTs). SAEs were defined as any related adverse medical events that could lead to death, life-threatening conditions, prolonged hospitalization, persistent or severe disability, or potential harm and requirement for clinical care. DLTs was defined as (1) cardiopulmonary decomposition after 6 days of treatment, (2) FiO2 that was increased by more than $30 \%$ compared with the previous level, (3) mean airway pressure increased by more than $5 \mathrm{~cm} \mathrm{H}_{2} \mathrm{O}$, (4) anaphylaxis or (5) death within 6 hours. The secondary outcomes included mechanical ventilation duration and duration of oxygen.

Statistical analysis of the data and meta-analysis were performed using Stata 16.0. P-values of 0.05 or less were considered statistically significant. Measurement data used the mean difference (MD) as the effect indicator, and categorical variables used the relative risk $(\mathrm{RR})$ as the effect indicator. Each effect size was given a point estimate and $95 \%$ CI. The chi-square test was used to evaluate the statistical heterogeneity between the results of the studies (test level $\alpha=0.1$ ). If there was no statistical heterogeneity between the studies $\left(I^{2}<50 \%, \mathrm{P}>0.1\right)$, a fixed-effects model was used for the meta-analysis; after excluding the effects of obvious clinical heterogeneity, a random-effects model was used for the meta-analysis. If there was obvious clinical heterogeneity in the results of each study, a subgroup analysis was performed. The inspection level of the meta-analysis was set to $\alpha=0.05$.

\section{RESULTS}

A total of 795 studies were found the databases, and 15 documents were selected by title and abstract. After full-text evaluation, a total of 7 clinical studies met the inclusion criteria. A flow chart of the process for eliminating studies is shown in Figure 1. All of the included clinical studies were published between 2014 and 2020. Among them, 4 were clinical controlled trials, and 3 were non-controlled clinical studies. Yun et al. ${ }^{25}$, Xian et al. ${ }^{26}$ and Steven et al. ${ }^{27}$ treated patients with MSCs infusions. Zhu et al. ${ }^{28}$ and Jie et al. ${ }^{29}$ 
administered autologous cord blood cells to infants. All the subjects in the 7 studies were premature infants with gestational ages of less than 37 weeks. All the infants weighed less than $2500 \mathrm{~g}$. The characteristics of the included relevant studies are shown in Table 1.

Four clinical controlled trials of the included articles evaluated the primary outcomes, including the number of deaths, BPD cases, SAEs and DLTs. The primary outcomes are shown in Table 2. Analysis of the clinical controlled trials revealed no significant statistical differences between the trial and control groups in the number of deaths (OR [95\% CI]: 0.619 [0.089, 4.316]) or BPD incidence (OR [95\% CI]: 1.138 [0.040, 32.36]). The incidence of SAEs (Figure 2a) and DLTs (Figure 2b) was not significantly different between the two groups. All SAEs that occurred in the clinical controlled trials were evaluated and had no relationship with human stem cells infusion.

Regarding the secondary outcomes, there was a significant statistical difference between the trial and control groups in the mechanical ventilation duration $(\mathrm{P}=0.01$, Figure $3 \mathrm{a})$ and the duration of oxygen administration $\left(\mathrm{P}=0.02\right.$, Figure $\left.3^{\mathrm{b}} \mathrm{b}\right)$. Based on the subgroup analysis, the incidence of SAEs was not significantly different with respect to whether a low or high dose of human stem cells was infused. The overall heterogeneity tests showed an $\mathrm{I}^{2}$ value of $14.9 \%$.

\section{DISCUSSION}

Our meta-analysis showed no statistically significant differences in deaths and SAEs in preterm infants receiving human stem cell transfusion compared with control infants. A total of 7 articles are included in this analysis, 3 clinical studies of which were uncontrolled trials. Steven et al. ${ }^{27}$ reported that 12 very-lowbirth-weight preterm infants were given intratracheal administration of human umbilical cord blood-derived mesenchymal stromal cells. In this study, only 1 infant died of pulmonary hypertension at 161 days of life. None of the SAEs evaluated were considered to be related to the MSCs infusion. Yang et al. ${ }^{29}$ infused autologous cord blood cells in 15 premature infants and assessed their safety. No BPD or deaths occurred in the infants who received the infusion. Five patients presented ventilation-associated pneumonia (VAP), but no SAEs were observed among them. In the subgroup analysis, the primary outcomes of SAEs and death were still not significantly different. These studies showed that human stem cells were safe for preterm infants. Yoon Ahn et al. ${ }^{30}$ conducted a study with 2 years of follow-up and found that it was safe to inject MSCs into the trachea of premature infants, with no side effects on the nervous system, growth or the respiratory system. However, to demonstrate whether the infusion of human cord blood stem cells is safe in preterm infants, large-sample clinical randomized controlled trials are still needed.

In this meta-analysis, there was no significant difference in the incidence of BPD between the two groups. However, we found that mechanical ventilation duration and duration of oxygen administration in the human stem cell groups were significantly shorter than those in the control groups (both $\mathrm{I}^{2}=0.00 \%$ ). Preclinical trials have confirmed that the infusion of mesenchymal stem cells can induce a reduction in BPD and pulmonary hypertension ${ }^{31,32}$. Xian $\mathrm{Wu}$ et al. ${ }^{26}$ enrolled 16 children diagnosed with moderate to severe BPD who were infused with MSCs, with subsequent monitoring and follow-up. The Silverman Anderson score of the experimental group was significantly lower than that of the control group. The peak volume ratio and tidal volume index obtained by the pulmonary function test were significantly better than those before treatment. The clinical care of premature infants involves multisystem comprehensive management. However, due to the small sample of included studies, the efficacy of stem cells in BPD still needs further clinical research.

\section{Conclusion}

Our analysis indicated that the infusion of human stem cells in premature infants does not increase the risk of SAEs or death. Since large-sample randomized controlled clinical trials have not been conducted, the present conclusions still need further experimental verification. Although the application of MSCs in premature infants has been proven to be safe in clinical trials, further research is needed to transform this therapy into clinical practice ${ }^{33}$.

\section{References}


1. Farstad T, Bratlid D, Medbo S, Markestad T. Bronchopulmonary dysplasia - prevalence, severity and predictive factors in a national cohort of extremely premature infants.Acta paediatrica (Oslo, Norway : 1992). Jan 2011;100(1):53-58.

2. Lin HJ, Du LZ, Ma XL, Shi LP, Pan JH, Tong XM, Li QP, Zhou JG, Yi B, Liu L, et al. Mortality and Morbidity of Extremely Low Birth Weight Infants in the Mainland of China: A Multi-center Study. Chinese medical journal. Oct 20 2015;128(20):2743-2750.

3. Bhunwal S, Mukhopadhyay K, Bhattacharya S, Dey P, Dhaliwal LK. Bronchopulmonary Dysplasia in Preterm Neonates in a Level III Neonatal Unit in India.Indian pediatrics. Mar 15 2018;55(3):211-215.

4. Isayama T, Lee SK, Yang J, Lee D, Daspal S, Dunn M, Shah PS. Revisiting the Definition of Bronchopulmonary Dysplasia: Effect of Changing Panoply of Respiratory Support for Preterm Neonates.JAMA pediatrics. Mar 1 2017;171(3):271-279.

5. Adams M, Bassler D, Bucher HU, Roth-Kleiner M, Berger TM, Braun J, Puhan MA, Edwards E, Soll R, Von Wyl V. Variability of Very Low Birth Weight Infant Outcome and Practice in Swiss and US Neonatal Units.Pediatrics. May 2018;141(5).

6. Lee JH, Noh OK, Chang YS. Neonatal Outcomes of Very Low Birth Weight Infants in Korean Neonatal Network from 2013 to 2016. Journal of Korean medical science. Feb 4 2019;34(5):e40.

7. Principi N, Di Pietro GM, Esposito S. Bronchopulmonary dysplasia: clinical aspects and preventive and therapeutic strategies. Journal of translational medicine. Feb 20 2018;16(1):36.

8. Burchert H, Lewandowski AJ. Preterm Birth Is a Novel, Independent Risk Factor for Altered Cardiac Remodeling and Early Heart Failure: Is it Time for a New Cardiomyopathy?Current treatment options in cardiovascular medicine. Feb 14 2019;21(2):8.

9. Laurie SS, Elliott JE, Beasley KM, Mangum TS, Goodman RD, Duke JW, Gladstone IM, Lovering AT. Exaggerated Increase in Pulmonary Artery Pressure during Exercise in Adults Born Preterm.American journal of respiratory and critical care medicine. Mar 15 2018;197(6):821-823.

10. Lewandowski AJ, Augustine D, Lamata P, Davis EF, Lazdam M, Francis J, McCormick K, Wilkinson AR, Singhal A, Lucas A, et al. Preterm heart in adult life: cardiovascular magnetic resonance reveals distinct differences in left ventricular mass, geometry, and function.Circulation. Jan 15 2013;127(2):197-206.

11. Villamor-Martinez E, Pierro M, Cavallaro G, Mosca F, Kramer BW, Villamor E. Donor Human Milk Protects against Bronchopulmonary Dysplasia: A Systematic Review and Meta-Analysis.Nutrients. Feb 20 $2018 ; 10(2)$.

12. del Cerro MJ, Sabate Rotes A, Carton A, Deiros L, Bret M, Cordeiro M, Verdu C, Barrios MI, Albajara L, Gutierrez-Larraya F. Pulmonary hypertension in bronchopulmonary dysplasia: clinical findings, cardiovascular anomalies and outcomes.Pediatric pulmonology. Jan 2014;49(1):49-59.

13. Thebaud B, Goss KN, Laughon M, Whitsett JA, Abman SH, Steinhorn RH, Aschner JL, Davis PG, McGrath-Morrow SA, Soll RF, et al. Bronchopulmonary dysplasia.Nature reviews. Disease primers. Nov $142019 ; 5(1): 78$.

14. Baud O, Trousson C, Biran V, Leroy E, Mohamed D, Alberti C. Association Between Early Low-Dose Hydrocortisone Therapy in Extremely Preterm Neonates and Neurodevelopmental Outcomes at 2 Years of Age.Jama. Apr 4 2017;317(13):1329-1337.

15. Yeh TF, Chen CM, Wu SY, Husan Z, Li TC, Hsieh WS, Tsai CH, Lin HC. Intratracheal Administration of Budesonide/Surfactant to Prevent Bronchopulmonary Dysplasia.American journal of respiratory and critical care medicine. Jan 1 2016;193(1):86-95.

16. Askie LM, Ballard RA, Cutter GR, Dani C, Elbourne D, Field D, Hascoet JM, Hibbs AM, Kinsella JP, Mercier JC, et al. Inhaled nitric oxide in preterm infants: an individual-patient data meta-analysis of 
randomized trials.Pediatrics. Oct 2011;128(4):729-739.

17. Askie LM, Davies LC, Schreiber MD, Hibbs AM, Ballard PL, Ballard RA. Race Effects of Inhaled Nitric Oxide in Preterm Infants: An Individual Participant Data Meta-Analysis. The Journal of pediatrics. Feb 2018;193:34-39.e32.

18. Chang YS, Choi SJ, Sung DK, Kim SY, Oh W, Yang YS, Park WS. Intratracheal transplantation of human umbilical cord blood-derived mesenchymal stem cells dose-dependently attenuates hyperoxia-induced lung injury in neonatal rats. Cell transplantation.2011;20(11-12):1843-1854.

19. Curley GF, Hayes M, Ansari B, Shaw G, Ryan A, Barry F, O’Brien T, O'Toole D, Laffey JG. Mesenchymal stem cells enhance recovery and repair following ventilator-induced lung injury in the rat.Thorax. Jun $2012 ; 67(6): 496-501$.

20. Chang YS, Ahn SY, Jeon HB, Sung DK, Kim ES, Sung SI, Yoo HS, Choi SJ, Oh WI, Park WS. Critical role of vascular endothelial growth factor secreted by mesenchymal stem cells in hyperoxic lung injury. American journal of respiratory cell and molecular biology. Sep 2014;51(3):391-399.

21. Augustine S, Avey MT, Harrison B, Locke T, Ghannad M, Moher D, Thebaud B. Mesenchymal Stromal Cell Therapy in Bronchopulmonary Dysplasia: Systematic Review and Meta-Analysis of Preclinical Studies.Stem cells translational medicine. Dec 2017;6(12):2079-2093.

22. Moher D, Shamseer L, Clarke M, Ghersi D, Liberati A, Petticrew M, Shekelle P, Stewart LA. Preferred reporting items for systematic review and meta-analysis protocols (PRISMA-P) 2015 statement.Syst Rev.Jan $12015 ; 4: 1$.

23. Cumpston M, Li T, Page MJ, Chandler J, Welch VA, Higgins JP, Thomas J. Updated guidance for trusted systematic reviews: a new edition of the Cochrane Handbook for Systematic Reviews of Interventions. The Cochrane database of systematic reviews. Oct 3 2019;10:Ed000142.

24. Schulz KF, Altman DG, Moher D. CONSORT 2010 statement: Updated guidelines for reporting parallel group randomised trials.J Pharmacol Pharmacother. Jul 2010;1(2):100-107.

25. Chang YS, Ahn SY, Yoo HS, Sung SI, Choi SJ, Oh WI, Park WS. Mesenchymal Stem Cells for Bronchopulmonary Dysplasia: Phase 1 Dose-Escalation Clinical Trial.Journal of Pediatrics. May 2014;164(5):966+ .

26. 吴羡. 人脐带间充质干细胞治疗儿童中重度支气管肺发育不良的临床研究[硕士], 重庆医科大学; 2019.

27. Powell SB, Silvestri JM. Safety of Intratracheal Administration of Human Umbilical Cord Blood Derived Mesenchymal Stromal Cells in Extremely Low Birth Weight Preterm Infants. The Journal of pediatrics. Jul 2019;210:209-213.e202.

28. Ren Z, Xu F, Zhang X, Zhang C, Miao J, Xia X, Kang M, Wei W, Ma T, Zhang Q, et al. Autologous cord blood cells infusion in preterm neonates safely reduces respiratory support duration and potentially preterm complications.Stem Cells Translational Medicine. Feb 2020;9(2):169-176.

29. Yang J, Ren Z, Zhang C, Rao Y, Zhong J, Wang Z, Liu Z, Wei W, Lu L, Wen J, et al. Safety of Autologous Cord Blood Cells for Preterms: A Descriptive Study.Stem Cells International. $20182018 ; 2018$.

30. Ahn SY, Chang YS, Kim JH, Sung SI, Park WS. Two-Year Follow-Up Outcomes of Premature Infants Enrolled in the Phase I Trial of Mesenchymal Stem Cells Transplantation for Bronchopulmonary Dysplasia.Journal of Pediatrics. Jun 2017;185:49-+.

31. Willis GR, Fernandez-Gonzalez A, Anastas J, Vitali SH, Liu X, Ericsson M, Kwong A, Mitsialis SA, Kourembanas S. Mesenchymal Stromal Cell Exosomes Ameliorate Experimental Bronchopulmonary Dysplasia and Restore Lung Function through Macrophage Immunomodulation.Am J Respir Crit Care Med. Jan $12018 ; 197(1): 104-116$. 
32. Augustine S, Cheng W, Avey MT, Chan ML, Lingappa SMC, Hutton B, Thébaud B. Are all stem cells equal? Systematic review, evidence map, and meta-analyses of preclinical stem cell-based therapies for bronchopulmonary dysplasia.Stem Cells Transl Med. Feb 2020;9(2):158-168.

33. Morita Y, Ema H, Nakauchi H. Heterogeneity and hierarchy within the most primitive hematopoietic stem cell compartment.J Exp Med. Jun 7 2010;207(6):1173-1182.

\section{Hosted file}

figure.pdf available at https://authorea.com/users/372512/articles/490519-safety-andeffectiveness-of-human-stem-cells-for-bronchopulmonary-dysplasia-in-preterm-infantsa-systematic-review-and-meta-analysis

\section{Hosted file}

table10.29.pdf available at https://authorea.com/users/372512/articles/490519-safety-andeffectiveness-of-human-stem-cells-for-bronchopulmonary-dysplasia-in-preterm-infants-asystematic-review-and-meta-analysis 